\title{
Lithium—Early Development, Toxicity, and Renal Function
}

\author{
Gordon Johnson, M.B., B.S., FRANZCP, FRCPsych, D.P.M.
}

The report of the effectiveness of lithium in the treatment of mania by John Cade was followed by a number of studies confirming his observations and developing guidelines for safe and effective use. Premature rejection of lithium on safety grounds denied many patients the benefit of treatment and may have cost more lives than it saved. A similar safety alarm was triggered by reports of kidney damage in the late 1970s. Subsequent reports have questioned the significance of anatomical findings, and functional impairment and relationship to lithium treatment. Recent findings support the conclusion that progressive impairment of glomerular and tubular function in patients during lithium maintenance is the exception rather than the rule and is related more to lithium intoxication, maintenance plasma lithium levels, concurrent medications, somatic illness, and age than on time on lithium. Guidelines for lithium use and monitoring of renal function are outlined.

[Neuropsychopharmacology 19:200-205, 1998]

(C) 1998 American College of Neuropsychopharmacology. Published by Elsevier Science Inc.
KEY WORDS: Lithium; Mania; Early development; Toxicity; Renal function

In 1949, John Cade reported in the Medical Journal of Australia, in a now historic article, the results of administration of lithium salts to patients with psychotic excitement. He described the effects in 10 manic patients, of whom three suffered from chronic, and the remainder from recurrent, mania. In addition, similar treatment was given to six patients with dementia precox and three melancholics. Although the manic patients showed marked improvement within the first 2 weeks of starting lithium, clnical remission occurring in eight patients, those with dementia precox or melancholia, did not show any fundamental improvement. The dis-

From the Department of Psychological Medicine, The University of Sydney, Sydney, New South Wales, and Mood Disorder Unit, Northside Clinic, Greenwich, New South Wales, Australia.

Address correspondence to: Dr. G. Johnson, Room 4, University of Sydney Clinical Science Building, Repatriation General Hospital, Hospital Road, Concord, 2139, NSW, Australia.

Received February 23, 1998; accepted February 23, 1998. covery of a specific chemical therapy that, without inducing sedation, could effectively remove the violence and extravagance of manic patients' behaviors, was a momentous discovery.

Telling his story of lithium, Cade commented that it was an unexpected, but inevitable, byproduct of experimental work to test a hypothesis regarding the etiology of manic depressive illness. Testing this hypothesis, he searched for evidence of toxic substances in the urine of manic patients. His experiments led him to focus on lithium urate. It was while determining the toxicity of lithium in guinea pigs that Cade noted they became extremely lethargic and unresponsive to stimuli. It may seem to be a long stretch from lethargy in guinea pigs to the control of manic excitement, but because these investigations had commenced in an attempt to demonstrate some possibly excreted toxin in the urine of manic patients, the association of ideas is understandable.

So struck was Cade by his observations of the effects of lithium on patients with mania that he stated it is so specific, it inevitably leads to speculation as to the possible etiological significance of a deficiency in the body of lithium ions in the genesis of this disorder. 
Cade first tested the doses he had selected for clinical use on himself. Single or repeated doses of either citrate or carbonate did not produce any discernable ill effects. However, in practice, he found a high proportion of patients showed toxic symptoms in 1 to 3 weeks, the symptoms of overdose being referable mainly to the alimentary and nervous systems. He was aware of the risks of severe toxicity, pointing out that, in these cases, immediate cessation of intake was required because there was little doubt that they could progress to fatality. It was the question of lithium toxicity that was to cast a pall on Cade's discovery. In particular, reports appearing concurrently in the United States concerning fatalities in patients with heart disease receiving lithium as a salt substitute led to lithium's being regarded as a dangerous drug (Talbot 1950).

In Australia, however, interest in lithium treatment was aroused. Noack and Trautner (1951) published the results of lithium treatment in a series of 100 hospitalized patients with, as they put it, various "mental affections." Noack was a psychiatrist from the Mont Park Hospital in Melbourne and Trautner a physiologist from the University of Melbourne. They reported that the effect on mania was striking, with 25 of 30 patients responding to lithium alone. They were the first to specifically draw attention to the ability of lithium to prevent relapse of mania in 20 patients stabilized on a maintenance dose and observed over 12 to 18 months. They studied the relationship of toxic symptoms to therapeutic effects and noted that the lithium level necessary to terminate mania is probably always reached only by near-toxic dosage. They reported some preliminary observations on lithium dosage and plasma level and described the practical clinical steps they had used in avoiding toxicity and observed that they encountered no incidence of grave intoxication.

A similar favorable report was published by Ashburner (1950) from Sunbury Mental Hospital. This report does not contain much detail; however, he stated that the cases treated as his hospital amply confirmed the value of Cade's discovery, which should stand as an important original contribution. Adding weight to this argument, he wrote, "as a measure of our experience with lithium, it may be of interest to state that already 13 pounds of the carbonate and 2 pounds of the citrate have been consumed by the patients at this hospital."

Glesinger (1954), a psychiatrist at the Claremont Hospital in Western Australia, reported treatment of 104 patients. The paper is interesting, because it addresses in depth the nature of lithium toxicity he rightly attributed to central nervous system changes. There was one fatality in this series with postmortem findings of encepalopathy. Because lithium is a metal ion, he raised the question of renal toxicity, carried out regular urinalyses, and reported two cases of albuminuria associated with irregularity in the concentrating and diluting ability of the kidneys.
In relation to the concern about toxicity that was emerging, Noack was at pains to emphasize "that in view of the very beneficial effect of this drug in cases of mania, it does not appear justified to abandon lithium as a form of medication solely because some fatal cases have been reported in which lithium poisoning has been incriminated. It appears, rather, that attempts should be made to establish clinical criteria which will result in a better selection of suitable cases," and I might add, appropriate monitoring procedures. These were what Noack and Traunter et al. (1955), were able to provide in their paper on how lithium behaves in the body. this was a definitive study on the physiology of lithium in patients and healthy subjects, carried out in collaboration with Morris and Gershon. They were the first to describe the patterns of lithium retention and excretion following single and multiple dose, and the changes in electrolyte and water balances that followed lithium administration and its course. The relationship between lithium dose and plasma level at "steady-state" conditions and the usefulness of plasma lithium concentrations in monitoring lithium balance were established. The effects of mania on lithium balance were studied, with the intriguing observations of lithium retention prior to mania breaking with subsequent lithium elimination, the reasons for which still lack adequate explanation. They also reported on the relationship between plasma level and toxicity. They laid the groundwork for clinical and laboratory monitoring and, taken in conjunction with the critical placebo-controlled study of Schou et al. (1954), confirming the observations of Cade, set the stage that would have allowed the safe and effective use of lithium. However, the profession turned against lithium both here and overseas. Premature rejection of lithium on safety grounds denied many patients effective treatment and cost more lives than it might have saved.

Another 15 years were to pass before the use of lithium was enthusiastically embraced, and John Cade's contribution was internationally recognized. He was a great Australian, and I am sure that he would have been honored that the John Cade Memorial Lithium Symposium acknowledges his important work.

Another safety alarm was triggered by reports of kidney damage in 1977 (Hestbech et al. 1977). In this instance, more rigorous evaluation and sober judgment prevailed. Initial safety reports were found to be grossly overestimated.

Uncertainty concerning lithium's effects on renal function are widespread and may adversely effect clinical management. The current status of lithium and renal function is reviewed here.

Thirst and increase of urine volume are two of the most frequently reported side effects of lithium in clinical practice (Johnson 1984). These changes have been attributed to decreased responsiveness of the renal tubule 
to the action of antidiuretic hormone (Bayliss and Heath 1978), which in some cases, may progress to nephrogenic diabetes insipidus.

The collecting tubule of the kidney has been identified as the site of action. Lithium accumulates in the collecting tubular cells after entering through sodium channels in the transluminal membrane. The mechanism whereby lithium interferes with the action of $\mathrm{ADH}$ is not fully understood but its primary effect seems to be decreased stimulation of adenyl cyclase, leading to decreased intracellular formation of cAMP. Action at a point distal to the cAMP formation has also been suggested (Boton et al. 1987). In addition, an acute histological lesion on the distal nephron corresponding to the site of lithium inhibition of $\mathrm{ADH}$ and consisting of epithelial cellular swelling and glycogen deposition has been reported (Walker 1993). Both functional and histological lesions occur early in the course of lithium therapy and seem to be readily reversible. Long-term lithium therapy is associated with impairment of urinary concentrating ability in up to $50 \%$ of patients with polyuria of greater than 3 liters per 24 hours in $20 \%$ of patients (Boton et al. 1987). Such increased urine volume carries a potential risk to the patients because of sodium depletion, excessive fluid loss, or reduced intake. In 5 to $10 \%$ of patients, the impairment of urinary concentrating ability may be irreversible or only partly reversible upon lithium discontinuation (Bendz 1983). An associated, non-specific interstitial nephropathy on renal biopsy has been reported (Hestbech et al. 1977). However, similar renal histopathology has been reported in psychiatric patients who have never received lithium (Walker et al. 1982).

In contrast, glomerular function remains relatively unscathed. Johnson et al. (1984) found a mild-to-moderate decrease in $15 \%$ of patients, with a fall in glomerular filtration rate (GFR) correlated with age. They concluded that progressive impairment of glomerular and tubular function during lithium maintenance is related more to age, episodes of lithium intoxication, and concurrent drug administration, than it is to duration of lithium treatment.

Lokkegard et al. (1985) stated that more extended periods of time on lithium would be necessary to detect a subtle, but progressive, decline in glomerular function. Recent prospective studies with extended duration of treatment of 10 or more years allow a more definitive assessment of whether duration of treatment is significantly correlated with progressive renal impairment. These are shown in Table 1.

Hetmar et al. (1991) reported on 19 patients out of 46 who had previously participated in a retrospective functional morphological study and had maintained lithium therapy and were available for follow-up 10 years later. At the time of the initial retrospective evaluation, they had been on lithium for a mean period of 10 years. They reported a decline in glomerular filtration rates that correlated with age. No significant changes in maximum concentrating ability were recorded. Included, however, were two patients with progressive renal insufficiency, in one of whom there was a probable episode of lithium toxicity. The authors' comment that maintenance lithium levels had fallen from the initial retrospective evaluation, and, at the time of the follow-up study, there was a mean serum level of 0.8 mmols/l.

Povlsen et al. (1992) in a related study, reported an 8 -year follow-up on 10 out of 43 patients who were tested prior to and following continuing lithium therapy for an average of 8.5 years. Only two patients, however, were on lithium only, the other patients received combinations with either tricyclic antidepressants, or both antidepressants and antipsychotic drugs. They reported a modest, but significant, increase in serum creatinine values, but a nonsignificant decrease in endogenous creatinine clearance that was not greater than might be expected in the case of increased age. No significant impairment of tubular function following lithium treatment was shown. The mean maintenance lithium level was $0.77 \mathrm{mmol} / \mathrm{l}$.

A report by Kallner and Patterson (1995) involving a cross-sectional study on 207 patients who had been receiving lithium from 1 to 30 years, included 50 patients who had been tested 5 and 10 years previously. Glomerular filtration rate changed only little with increasing treatment duration, but there were more values lower than the reference range in patients treated for 15 or more years than in those treated for a shorter time. There

Table 1. Lithium and Renal Function

\begin{tabular}{|c|c|c|c|c|c|c|}
\hline \multicolumn{2}{|l|}{ Prospective Studies } & \multirow{2}{*}{$\begin{array}{l}\text { Duration Lithium } \\
\text { Treatment (Years) }\end{array}$} & \multirow{2}{*}{$\begin{array}{l}\text { Serum Lithium } \\
(\mathrm{mmol} / \mathrm{l})\end{array}$} & \multirow{2}{*}{$\begin{array}{l}\text { Mean } \\
\text { Age }\end{array}$} & \multicolumn{2}{|c|}{ Renal Function } \\
\hline Study & $N$ & & & & GFR & U Max \\
\hline Hetmar et al. (1991) & 19 & $10+(10)$ & 0.8 & 58 & $\begin{array}{l}\text { Decrease correlated with } \\
\text { age }\end{array}$ & No change \\
\hline Povlsen et al. (1992) & 10 & 8 & 0.77 & 47 & No change & No change \\
\hline Kallner and Patterson (1995) & 207 & $1-30$ & $0.6-0.8$ & 56 & $\begin{array}{l}\text { No significant changes in } \\
50 \text { patients tested } 5 \text { and } \\
10 \text { years previously }\end{array}$ & \\
\hline
\end{tabular}


Table 2. Lithium and Renal Function

\begin{tabular}{|c|c|c|c|c|c|c|}
\hline \multicolumn{2}{|c|}{ Cross-Sectional Studies } & \multirow{2}{*}{$\begin{array}{l}\text { Duration Lithium } \\
\text { Treatment (Years) }\end{array}$} & \multirow{2}{*}{$\begin{array}{l}\text { Serum Lithium } \\
(\mathrm{mmol} / \mathrm{l})\end{array}$} & \multirow{2}{*}{$\begin{array}{l}\text { Mean } \\
\text { Age }\end{array}$} & \multicolumn{2}{|c|}{ Renal Function } \\
\hline Study & $N$ & & & & GFR & U Max \\
\hline Bendz et al. (1994) & 142 & 15 & 0.65 & 61 & Reduced $20 \%$ & $\begin{array}{c}12 \%<300 \\
\text { m0sm01 }\end{array}$ \\
\hline Kehoe (1994) & 740 & 5 & $\mathrm{~N} / \mathrm{A}$ & 54 & $\begin{array}{l}\text { Decline correlated } \\
\text { with age }\end{array}$ & $\mathrm{N} / \mathrm{A}$ \\
\hline Walker et al. (1996) & 20 & 20 & $\mathrm{~N} / \mathrm{A}$ & $\mathrm{N} / \mathrm{A}$ & Reduced $10 \%$ & \\
\hline
\end{tabular}

were no significant changes in urinary concentrating ability and no cases of renal insufficiency.

These studies with more extended duration of treatment contain small patient numbers that limit conclusions. However, the results are consistent with a weak or no correlation between time on lithium and progressive renal impairment. Cross-sectional studies are less informative in assessing lithium's specific changes; however, they do identify the extent of impaired renal function in patients currently receiving lithium maintenance and likely risk factors. These are shown in Table 2.

Bendz et al. (1994) reported a cross-sectional study of 142 patients with more than 15 years of cumulative lithium treatment. Mean age of patients was 61 years, with a mean serum lithium level of $0.65 \mathrm{mmol} / \mathrm{l}$. Glomerular filtration rate was reduced in $21 \%$ of patients, with a reduction of urinary concentrating capacity in $44 \%$, with nephrogenic diabetes insipidus in $12 \%$ of the total patient group. Renal function was more reduced in patients on lithium combined with other psychotropic medications, in patients with cardiovascular disease, and in those receiving concomitant treatment for somatic disorders. Thirteen patients had had an episode of lithium intoxication, two of whom had a reduced GFR and one who had reduced urinary concentrating ability. Patients with impaired renal function received a higher but insignificant cumulative lithium dose. Bendz et al. (1994) reported that renal morbidity increases in parallel with increasing exposure to lithium treatment.

Kehoe (1994), in a study of glomerular function in 740 unselected lithium patients, reported that lithium treatment duration and glomerular filtration were weakly related. Also, cases exposed to higher lithium concentrations greater than $0.6 \mathrm{mmol} / 1$ had lower creatinine clearance than those maintained at serum levels less than $0.6 \mathrm{mmol} / 1$.

In a cohort of 20 patients on maintenance lithium followed for more than 20 years, Walker et al. (1996) reported a moderate impairment of GFR in two patients (serum creatinine greater than $0.20 \mathrm{mmol} / \mathrm{l}$ ). One patient had a history of recurrent episodes of acute lithium toxicity. All patients at some time had had polyuria; i.e., urine volumes greater than 3 liters in 24 hours documented. Risk factors identified as associated with impairment of renal function in lithium-treated patients are shown in Table 3.

Hestbech et al. (177) in his renal morphological functional study in 14 patients, 10 of whom had current or previous episodes of lithium intoxication, concluded "it is possible that chronic renal disease may only develop in patients where the renal concentration of lithium periodically or continual reaches toxic levels." Prior intoxication has been implicated in impairment of renal function in a number of reports (Aurell et al. 1981; Hansen 1981).

The most systematic study of renal function and lithium intoxication was reported by Johnson et al. (1984). They found a prior history of one or more episodies of lithium intoxication in 30\% of patients and a significant correlation between falling glomerular filtration rate and severity of lithium intoxication. Such factors as volume depletion because of fluid loss, electrolyte disturbance, or direct effects of lithium may be implicated in irreversible changes in renal function in states of prolonged intoxication. High maintenance plasma lithium levels of greater than $1.0 \mathrm{mmol} / 1$ narrow the safety margin.

There is a negative correlation between maintenance serum levels and urinary concentrating ability, as shown in Figure 1. Changes in urinary concentrating ability are highly sensitive to maintenance plasma lithium levels. In a prospective study of 40 lithium-treated patients with renal function assessments at 6 to 18 months apart, De Paulo et al. (1986) reported significant changes in 24-hour urine volume with changes in mean plasma lithium levels. Bendz et al. (1994) reported a significant negative correlation between lithium dose and urinary concentrating capacity. It is now generally accepted that higher maintenance plasma lithium levels

Table 3. Risk Factors Associated with Impaired Renal Function in Patients on Lithium

- Lithium intoxication

- Lithium dose and plasma level

- Concomitant medication

- Chronic physical illness

- Age 


\section{- Lithium Only}

- Lithium Plus Other Medication

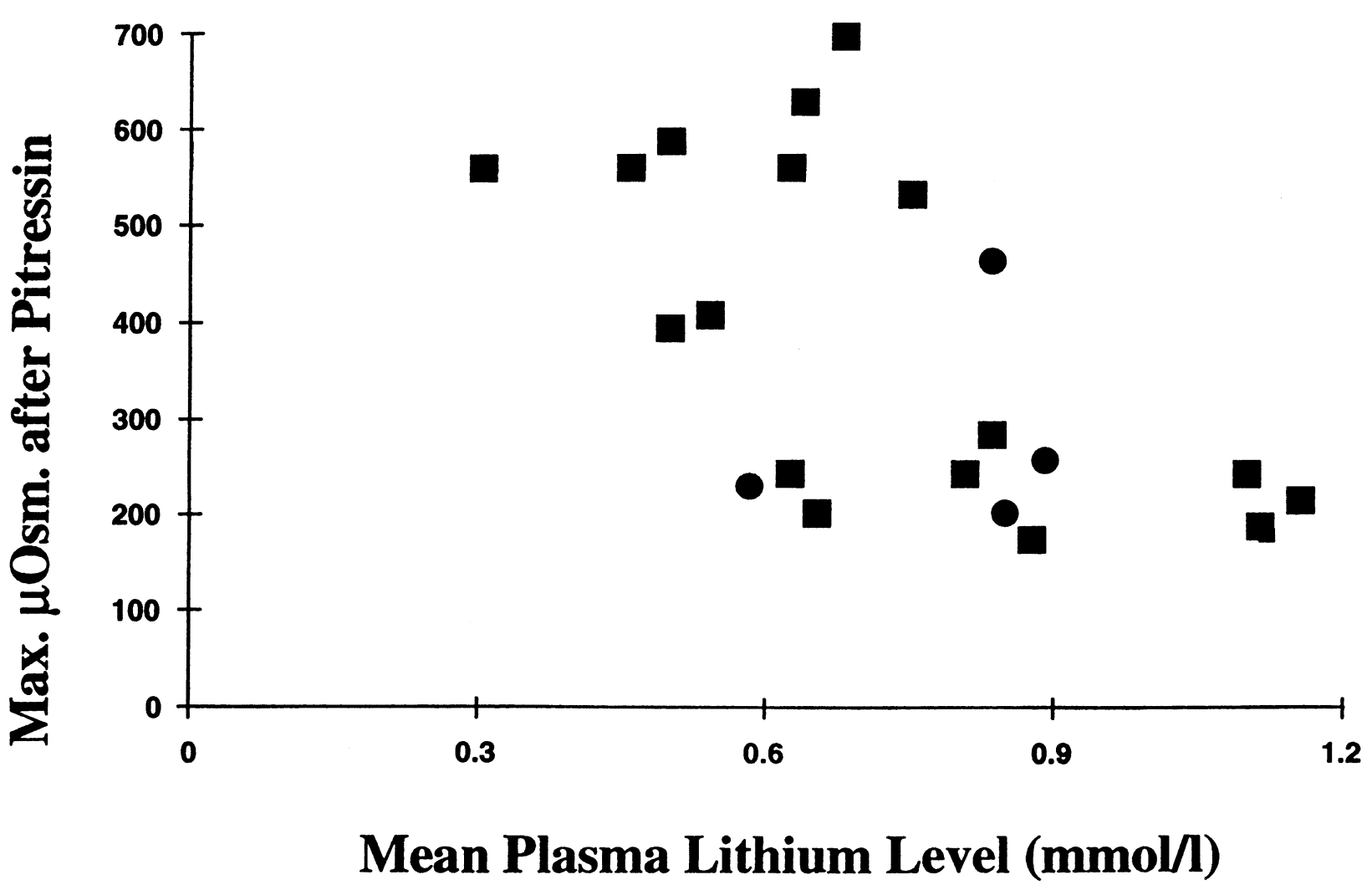

Figure 1. Maintenance serum lithium levels (mmols $/ \mathrm{l}$ ) and maximum urinary concentrating ability (mosm/ $\mathrm{kg}$ water) $\mathbf{\square}$ in patients on lithium only. in patients on lithium plus concomitant medication. Mean duration of lithium threatment 6 years.

initially advocated for maintenance were associated with a significantly higher risk of impairment of renal function.

A number of studies have reported that impairment of urinary concentrating capacity is greater in patients receiving other concomitant psychotropic medication or other drugs (Johnson et al. 1984; Bendz et al. 1994). This is also suggested from studies that found tubulointerstitial damage in psychiatric patients taking drugs other than lithium (Walker et al. 1982). Patients showing renal impairment are older and have such chronic physical illness as cardiovascular disease, which may have direct effects on renal function.

\section{CLINICAL IMPLICATIONS}

Appropriate baseline assessment prior to lithium treatment will identify patients at significant risk. Renal disease is not an absolute contraindication to lithium treatment, but it requires close collaboration between psychiatrist and the renal physician. Standard laboratory assessments include serum creatinine, urea and electrolytes, and urinalysis. Measurements of urinary concentrating capacity and glomerular filtration rates should be undertaken as indicated.

During maintenance treatment, monitoring of renal function should include routine questioning concerning urine output and thirst. Polyuria and nocturia are sensitive indicators of lithium's effects on renal concentrating capacity. Thirst is less specific and more common with additional psychotropic drugs (Bendz et al. 1994). Emergence of polyuria requires assessment of urinary concentrating capacity and 24-hour urine volume. Progressive impairment requires full renal evaluation. Measurement of creatinine is recommended every 6 months.

High-maintenance plasma lithium levels and failure to monitor levels regularly expose the patient to significant risk. The majority of patients can be maintained 
satisfactorily at levels between 0.5 to $0.8 \mathrm{mmol} / \mathrm{l}$. Maintenance plasma lithium levels of greater than 1.0 $\mathrm{mmol} / 1$ should be avoided. Where polyuria emerges, downward adjustment of serum lithium levels within the therapeutic range has a significant effect in reducing impairment of urinary concentrating capacity in many patients, and enhancing compliance. In advancing age, there is a fall in GFR; and therefore, lithium elimination. Failure to adjust lithium dosage with rising plasma lithium levels exposes patients to lithium accumulation and intoxication.

Persistent polyuria, despite adjustment of plasma lithium levels, can be reduced with concomitant diuretic administration. Increased proximal lithium absorption will occur, however, requiring reduction of dose. Use of the potassium-sparing diuretic amiloride will avoid the need for potassium supplementation required with thiazide diuretics. Amiloride specifically blocks lithium entry to tubular cells by closing sodium channels, and because it could prevent the long-term accumulation of lithium, it has been suggested it could prevent the development of diabetes insipidus. It is less effective in patients with severe disease, because structural tubulointerstitial damage probably limits its effects.

Lithium has become the most frequent cause of nephrogenic diabetes insipidus, and management often involves shared care with a renal physician. It is important that psychiatrists do not abdicate their responsibility in decisions concerning benefit-to-risk assessments and continuation of cessation of lithium treatment.

\section{REFERENCES}

Ashburner J (1950): A case of chronic mania treated with lithium citrate and terminating fatally. Med J Australia $37: 386$

Aurell M, Svalander C, Wallin L, Alling C (1981): Renal function and biopsy findings in patients on long-term lithium treatment. Kidney Int 20:663-670

Bendz H (1983): Kidney function in lithium treated patients. Acta Psychiat Scand 68:303-324

Bendz H, Aurell M, Balldin J, Mathe A, Sjodin I (1994): Kidney damage in long-term lithium patients: A cross-sectional study of patients with 15 years or more on lithium. Nephrol Dial Transplant 9:1250-1254

Boton R, Gauiria M, Battle D (1987): Prevalence, pathogenesis, and treatment of renal dysfunction associated with chronic lithium therapy. Am J Kidney Dis 10:329-345
Cade J (1949): Lithium salts in the treatment of psychotic excitement. Med J Australia 2:349-352

De Paulo J, Correa E, Sapir D (1986): Renal function and lithium: A longtitudinal study. Am J Psychiatry 143:892895

Glesinger B (1954): Evaluation of lithium in treatment of psychotic excitement. Med J Australia 41:277-282

Hansen HE (1981): Renal toxicity of lithium. Drugs 22:461476

Hestbech J, Hansen HE, Amdisen A, Olsen S (1977): Chronic renal lesions following long-term treatment with lithium. Kidney Int 12:205-213

Hetmar O, Juul Povlsen U, Ladeforged J, Bolwig T (1991): Lithium: Long-term effects on the kidney. Brit J Psychiat 158:53-58

Johnson G (1984): Lithium. Med J of Australia 141:595-601

Johnson G, et al. (1984): Renal function and lithium treatment: Initial and follow-up tests in manic-depressive patients. J Aff Dis 6:249-263

Kallner G, Patterson U (1995): Renal, thyroid, and parathyroid function during lithium treatment: Laboratory tests in 207 people treated for 1-30 years. Acta Psychiat Scand 91:46-51

Kehoe R (1994): A cross-sectional study of glomerular function in 740 unselected lithium patients. Acta Psychiat Scand 89:68-71

Lokkegard H, Andersen N, Henriksen E, et al. (1985): Renal function in 153 manic depressive patients treated with lithium for more than five years. Acta Psychiat Scand 71:347-355

Noack C, Trautner E (1951): The lithium treatment of maniacal psychosis. Med J Australia 38:219-222

Povlsen U, Hetmar O, Ladeforged J, Bolwig T (1991): Lithium: Long-term effects on the kidney. Brit J Psychiat 158:53-58

Schou M, Juul-Nielsen N, Stromgren R, Voldby H (1954): The treatment of manic psychosis by the administration of lithium sals. J Neurol Neurosurg Psychiat 17:250-260

Talbot JM (1950): The use of lithium salts as substitutes for sodium chloride. Arch Int Med 85:1-2

Trautner E, Morris A, Noack C, Gershon S (1955): The excretion and retention of ingested lithium and its effect on the ionic balance of man. Med J Australia 2:280-291

Walker RG, Bennett WM, Davies BM, Kincaid-Smith P (1982): Structural and functional effects of long-term lithium therapy. Kidney Int Supp 11:S13-S19

Walker R (1993): Lithium nephrotoxicity. Kidney Int Supp 42:S93-S98

Walker R, Burrows G, Schweitzer I, Grounds D, Davies B (1996): Renal function after 20 years of lithium therapy. Paper presented at the Congress CINP, Melbourne 